Jurnal Keperawatan Silampari

Volume 3, Nomor 2, Juni 2020

e-ISSN: 2581-1975

p-ISSN: 2597-7482

DOI: https://doi.org/10.31539/jks.v3i2.1121

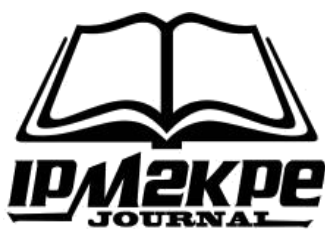

\title{
PERSEPSI PERAWAT TENTANG SUPERVISI KLINIS PELAKSANAAN EDUKASI PASIEN DAN KELUARGA
}

\author{
Yetty Mariani Tambun ${ }^{1}$, Setiawan ${ }^{2}$, Roymond H. Simamora ${ }^{3}$ \\ Universitas Sumatera Utara ${ }^{1,2,3}$ \\ yetty_tambun@yahoo.com ${ }^{1}$
}

\begin{abstract}
ABSTRAK
Tujuan penelitian ini adalah untuk menggali persepsi perawat tentang supervisi klinis pelaksanaan edukasi pasien dan keluarga di Rumah Sakit Universitas Sumatera Utara. Jenis penelitian yang digunakan adalah penelitian kualitatif dengan desain fenomenologi. Hasil penelitian ini memperoleh lima tema utama, yaitu (1) tujuan dilakukannya supervisi terkait pelaksanaan edukasi pasien dan keluarga, (2) metode dalam melaksanakan supervisi, (3) kendala yang dialami dalam melaksanakan supervisi, (4) harapan kedepan terkait pelaksanaan supervisi dan (5) manfaat pelaksanaan supervisi. Simpulan, persepsi perawat terhadap kegiatan supervisi klinis pelaksanaan edukasi pasien dan keluarga penting untuk dilakukan meskipun dalam pelaksanaannya masih belum optimal.
\end{abstract}

Kata Kunci: Edukasi, Rumah Sakit, Supervisi Klinis

\section{ABSTRACT}

The purpose of this study was to explore nurses' perceptions about clinical supervision in the implementation of patient and family education in Universitas Sumatera Utara. This type of research is a qualitative research with a phenomenological design. The results of this study brought out five main themes, namely (1) the purpose of supervision in the implementation of patient and family education, (2) methods of carrying out supervision, (3) the barriers that had been facing during the implementation supervision, (4) the future expectations related to the implementation of supervision and (5) the benefits of supervision implementation. Conclusions, nurses' perceptions about clinical supervision in the implementation patient and family education are important to do, even though the implementation still not optimum.

Keywords: Education, Hospital, Clinical Supervision

\section{PENDAHULUAN}

Pasien sebagai pengguna jasa pelayanan kesehatan menuntut agar pelayanan yang diberikan bermutu. Salah satu tuntutan pasien terhadap pelayanan kesehatan, yaitu mendapatkan kejelasan informasi kesehatan melalui pelaksanaan edukasi pasien dan keluarga. Edukasi pasien merupakan hak yang dimiliki pasien dan merupakan salah satu hal penting dalam meningkatkan kualitas layanan dan keselamatan pasien, sehingga edukasi pasien masuk dalam Standar Nasional Akreditasi Rumah Sakit (SNARS) Tahun 2018 (KARS, 2018). 
Pelaksanaan edukasi pada pasien dan keluarga di rumah sakit masih memiliki hambatan. Livne et al., (2017) menyatakan bahwa hambatan pelaksanaan edukasi di rumah sakit yaitu dikarenakan kelebihan beban kerja, kurangnya kebijakan dan pedoman mengenai edukasi pasien, prioritas dan tanggung jawab perawat yang rendah dalam memberikan edukasi pada pasien. Selain itu, ada juga hambatan lain yang berasal dari manajemen, yakni kurangnya komitmen terhadap penyediaan media edukasi pasien, kurangnya kepercayaan terhadap pentingnya pelaksanaan edukasi pasien, dan kurangnya supervisi atau tindakan pengawasan terhadap kinerja perawat dalam hal pemberian edukasi (Heshmati et al., 2016).

Supervisi atau tindakan pengawasan merupakan hal yang paling efektif dalam meningkatkan kinerja dan kompetensi tenaga kesehatan, dimana salah satunya, yaitu perawat (Bradley, 2019). Supervisi merupakan bagian dari fungsi pengarahan yang berperan dalam mempertahankan kegiatan yang telah diprogramkan agar dapat dilakukan dengan baik dan lancar (Nuritasari et al., 2020). Salah satu jenis supervisi yang mendukung lingkungan kerja yang positif dan memberikan hasil perawatan berkualitas yakni supervisi klinis (Cutcliffe et al., 2018). Supervisi klinis melibatkan hubungan antara supervisor (pelaksana supervisi) dan supervisee (orang yang disupervisi) dalam memfasilitasi pembelajaran reflektif.

Supervisi klinis dalam keperawatan telah ada di Inggris selama 24 tahun, tetapi belum wajib untuk dilakukan. Sebuah penelitian di Orkney telah berhasil menerapkan model supervisi klinis, yang hasilnya memberikan dampak pada peningkatan dukungan dan refleksi, serta meningkatkan hubungan yang lebih kuat dengan rekan perawat yang bekerja dilingkungan yang sama (Hall, 2018). Sementara itu, kegiatan supervisi klinis keperawatan di Indonesia masih belum jelas pelaksanaannya di rumah sakit. Hingga saat ini masih belum di ketahui seberapa tepat dan praktis model yang dapat diterapkan di rumah sakit (Yuswanto et al., 2018).

Beberapa penelitian menunjukkan bahwa pelaksanaan supervisi dirumah sakit memiliki hambatan. Penelitian Desi et al., (2017) menyatakan bahwa pelaksanaan supervisi di RSUD Panembahan Senopati Bantul menghadapi hambatan internal yaitu kurangnya motivasi dan hambatan eksternal yaitu beban pekerjaan ganda dan kurangnya penghargaan rumah sakit kepada supervisor, khususnya dalam hal honor dan juga belum terdapat program rutin dan berkala tentang monitor dan evaluasi kegiatan supervisi di RSUD Panembahan Senopati Bantul karena belum terdapat peraturan atau kebijakan yang mengaturnya.

Hambatan lain yang paling sering ditemukan dalam melaksanakan supervisi klinis adalah waktu. Efektivitas dan keberhasilan supervisi klinis sering tidak terlihat karena kurangnya waktu untuk melaksanakan kegiatan tersebut. Kurangnya waktu disebabkan oleh karena beban kerja sehingga kegiatan supervisi tidak dapat dilakukan secara teratur. Hal tersebut ditemukan sebagai penghambat yang mempengaruhi pelaksanaan supervisi klinis (McCarron et al., 2018; Ning, Costello, 2017). Beberapa penelitian telah menunjukkan adanya kesulitan atau hambatan dalam melaksanakan supervisi klinis. Oleh karena itu, hambatan yang dialami tersebut harus segera diatasi agar perawat maupun organisasi pelayanan kesehatan dapat merasakan manfaat supervisi klinis.

Schaffarczyk (2018) mengungkapkan bahwa melalui supervisi klinis, terjadi peningkatan kepercayaan diri, memberikan kesempatan untuk merefleksikan praktik, dapat saling berbagi ide dengan rekan-rekan perawat, dan dapat membandingkan praktik yang telah dilakukan dengan sudut pandang ataupun pengalaman rekan yang lain sehingga dapat memperoleh pengetahuan yang baru. Selain itu, supervisi klinis juga 
dapat membantu mengurangi terjadinya insiden dalam tindakan perawatan, meningkatkan kepuasan kerja, meningkatkan retensi dan efektivitas staf dengan mendukung peningkatan kualitas, mengelola resiko, dan meningkatkan akuntabilitas perawat di rumah sakit (Cutcliffe et al., 2018).

Rumah Sakit Universitas Sumatera Utara merupakan salah satu tempat pelayanan kesehatan yang berada di Kota Medan yang turut berkontribusi dalam pelayanan kesehatan pada masyarakat. Undang-Undang No. 38 tahun 2014 dan Undang-Undang No. 36 tahun 2009 merupakan dasar atas hak dan kewajiban tenaga kesehatan termasuk perawat dalam melaksanakan tugas-tugas pada pelayanan kesehatan. Dalam UndangUndang Nomor 38 tahun 2014 dinyatakan bahwa, salah satu peran perawat dalam melaksanakan pelayanan kesehatan, yaitu sebagai penyuluh. Sebagai penyuluh, perawat berwenang memberikan penyuluhan kepada pasien mengenai informasi kesehatan sebagai upaya menciptakan perilaku yang bersih dan sehat.

Pemberian informasi dan edukasi kepada pasien dan keluarga di Rumah Sakit Universitas Sumatera Utara ditetapkan dalam keputusan Direktur Nomor: 1346/UN5.4.11/SJM/2016. Berdasarkan hasil wawancara dengan empat orang Kepala ruangan di Rumah Sakit Universitas Sumatera Utara, didapatkan bahwa pelaksanaan edukasi pasien dan keluarga masih belum dilaksanakan secara optimal. Media untuk pemberian edukasi belum ada.

Kepala ruangan sebagai supervisor perlu melakukan supervisi klinis agar perawat pelaksana dapat meningkatkan dan mempertahankan pelaksanaan edukasi pasien dan keluarga sesuai dengan standar yang telah ditetapkan. Supervisi apabila dilakukan secara efektif, maka dapat menjadi garansi keselamatan yang dapat meningkatkan kepuasan pasien akan pelayanan keperawatan yang diberikan.

Selama ini di tempat penelitian sudah dilakukan edukasi pada pasien dan keluarga serta beberapa penelitian sebelumnya hanya menjelaskan tentang edukasi dan persepsi saja. Namun penelitian ini memfokuskan pada persepsi perawat tentang supervisi klinis pelaksanaan edukasi pada pasien dan belum pernah dilakukan di tempat penelitian. Penelitian ini bertujuan untuk mengetahui persepsi perawat mengenai supervisi klinis pelaksanaan edukasi pasien dan keluarga di Rumah Sakit Universitas Sumatera Utara.

\section{METODE PENELITIAN}

Penelitian ini menggunakan pendekatan kualitatif fenomenologi untuk mengeksplorasi persepsi perawat. Partisipan dalam penelitian ini adalah perawat yang terlibat langsung dalam pelaksanaan supervisi klinis di Rumah Sakit Universitas Sumatera Utara yang terdiri dari Kepala Seksi Keperawatan, Kepala Ruangan, Ketua Tim dan perwakilan Perawat Pelaksana. Jumlah partisipan dalam penelitian ini adalah sebanyak 22 partisipan, yakni meliputi 16 orang supervisor pada kegiatan Focus Group Discussion (FGD) dan 6 orang perawat pelaksana pada kegiatan in-depth interviews.

Data dikumpulkan melalui metode Focus Group Discussion (FGD) dan in-depth interviews dengan waktu kurang lebih 60 menit. Pada saat melakukan Focus Group Discussion (FGD) dan in-depth interviews, peneliti menggunakan panduan Focus Group Discussion (FGD) dan in-depth interviews sebagai alat bantu dalam mengajukan pertanyaan kepada partisipan. Data yang diperoleh dari Focus Group Discussion (FGD) dan in-depth interviews di buat dalam bentuk transkrip dan transkrip tersebut kemudian dianalisis dengan menggunakan teknik content analysis. 
HASIL PENELITIAN

Tabel. 1

Karakteristik Demografi Partisipan

(Supervisor dan Perwakilan Perawat Pelaksana)

\begin{tabular}{llrrrr}
\hline & & \multicolumn{2}{c}{ Supervisor } & \multicolumn{2}{c}{ Perawat pelaksana } \\
\cline { 2 - 6 } No. Karakteristik & \multicolumn{2}{c}{$\mathrm{n}=16$} & \multicolumn{3}{c}{$\mathrm{n}=6$} \\
\cline { 2 - 6 } & $\mathrm{f}$ & $\%$ & $\mathrm{f}$ & $\%$ \\
\hline 1. Usia & 7 & 43,8 & 6 & 100 \\
& 26-35 tahun & 9 & 56,3 & 0 & 0 \\
36-45 tahun & & & & \\
Jenis kelamin & 0 & 0 & 1 & 16,7 \\
Laki-laki & 16 & 100 & 5 & 83,3 \\
Perempuan & & & & \\
3endidikan & 1 & 6,3 & 4 & 66,7 \\
D3 Keperawatan & 13 & 81,3 & 2 & 33,3 \\
S1 Keperawatan + Ners & 1 & 6,3 & 0 & 0 \\
S2 Keperawatan & 1 & 6,3 & 0 & 0 \\
S2 Kesehatan Masyarakat & & & & \\
Lama Bekerja & 7 & 43,8 & 5 & 83,3 \\
0-5 tahun & 6 & 37,5 & 1 & 16,7 \\
6-10 tahun & 3 & 18,8 & 0 & 0 \\
\hline >10 tahun & & & & \\
\hline
\end{tabular}

Berdasarkan tabel 1, diketahui bahwa sebagian besar supervisor berada pada kelompok usia 36-45 tahun, yaitu sebanyak 9 orang (56,3\%). Keseluruhan supervisor berjenis kelamin perempuan (100\%). Pendidikan terakhir supervisor ditemukan bervariasi, namun mayoritas memiliki pendidikan terakhir Ners, yaitu sebanyak 13 orang $(81,3 \%)$. Untuk lama bekerja, mayoritas supervisor memiliki lama bekerja $0-5$ tahun, yaitu sebanyak 7 orang $(43,8 \%)$. Sementara itu, karakteristik demografi partisipan pada kelompok perawat pelaksana menunjukkan bahwa mayoritas perawat pelaksana berada pada kelompok usia 26-35 tahun (100\%). Mayoritas berjenis kelamin perempuan, yaitu sebanyak 5 orang $(83,3 \%)$. Untuk tingkat pendidikan, ditemukan sebanyak 4 orang $(66,7 \%)$ memiliki pendidikan terakhir D3 Keperawatan. Untuk lama bekerja, mayoritas telah bekerja selama $0-5$ tahun, yaitu sebanyak 5 orang $(83,3 \%)$.

Hasil Focus Group Discussion (FGD) dan in-depth interviews yang dilakukan secara langsung dengan partisipan mengungkapkan 5 tema utama yang menggambarkan persepsi perawat tentang supervisi klinis pelaksanaan edukasi pasien dan keluarga. Tema-tema tersebut antara lain: (1) tujuan dilakukannya supervisi terkait pelaksanaan edukasi pasien dan keluarga, (2) metode dalam melaksanakan supervisi, (3) kendala yang dialami dalam melaksanakan supervisi, (4) harapan kedepan terkait pelaksanaan supervisi, dan (5) manfaat pelaksanaan supervisi.

\section{Tema 1: Tujuan Dilakukannya Supervisi Terkait Pelaksanaan Edukasi Pasien dan Keluarga}

Partisipan menyampaikan tujuan dilakukannya supervisi, yaitu supervisi merupakan hal yang penting dilakukan sesuai dengan kompetensi yang harus dicapai perawat, untuk menilai kemampuan perawat dalam menyampaikan informasi kesehatan pada pasien, untuk memantau dokumentasi pemberian edukasi, meningkatkan percaya diri perawat, agar jelas edukasi yang disampaikan perawat, pelayanan keperawatan lebih bermutu dan efisien, meningkatkan pengetahuan dan pemahaman perawat, pasien lebih mengenal perawat yang merawatnya, mencegah terjadinya miskomunikasi dengan 
keluarga pasien, dan untuk kebaikan perawat agar bekerja sesuai dengan SPO. Berikut pernyataan langsung dari partisipan:

"Perawat kan ada logbooknya. Di logbook itu kan pemberian edukasi ada, disitu dia harus di supervisi.." (Partisipan 12)

"Perlu. Karena misalnya PP yang edukasi ke keluarga pasien, kan ada juga PP ini yang tata bahasanya itu bagus gak. Ada yang seperti itu. Jadi, disitu kita bisa menilai kira-kira bahasa dia itu bagus gak. Baru, materi yang disampaikannya nyampe gak. Gitu" (Partisipan 3)

"Supaya pelayanan ke depannya lebih bermutu dan lebih efisien. Untuk mengendalikan mutu dan biaya. Terus, agar perawat yang disupervisi lebih pintar, lebih percaya diri" (Partisipan 1)

"Supaya perawatnya lebih percaya diri. Terus, supaya informasi yang disampaikan tidak bersalahan atau simpang siur" (Partisipan 13)

"Penting juga sih menurutku. Jadi perawat nanti lebih paham apa aja yang mau disampaikan saat edukasi. Jadi supervisor memberi tahu kepada perawat saransarannya, hal-hal yang diperlukan lagi untuk edukasi. Ya jadi gitu kita lebih tahu lebih detail dan mendalam apa aja yang perlu kita edukasi” (Partisipan 19)

"Terus, untuk pasien agar pasien mengenal siapa perawat yang merawatnya.." (Partisipan 14)

"Itu wajib lah. Wajib dilakukan. Namanya kita perawat kan emosional kita sewaktuwaktu bisa berubah. Tergantung dengan tekanan pekerjaan atau dengan ya kita manusia punya masing-masing sifat. Takutnya ada salah penyampaian jadi harus diperbaiki. Jadi, tetap kita harus di monitoring. Gitu. Takutnya ada miskomunikasi dengan keluarga pasien jadi bisa di diskusikan.." (Partisipan 18)

"Supervisi sendiri itu untuk kebaikan kami waktu bekerja dan edukasi yang lain juga baiknya juga di supervisi sama kepala ruangan dan kerja pun nanti jadi sesuai SOP..” (Partisipan 22)

\section{Tema 2: Metode dalam Melaksanakan Supervisi}

Partisipan menyampaikan ada beberapa metode yang dilakukan dalam melaksanakan supervisi, yaitu dilakukan secara berjenjang, dilakukan secara menyeluruh atau tidak terpisah-pisah, melakukan supervisi secara tiba-tiba atau tanpa perencanaan, dilakukan secara situasional, dilakukan saat operan dan dilakukan saat ada suatu masalah atau hambatan. Berikut pernyataan langsung dari partisipan:

"Kan edukasi pasien kan berarti yang megang asuhan keperawatan. Berarti di kepala ruangan aja untuk edukasi. Kepala ruangan ke ketua tim. Ketua tim ke PP” (Partisipan 2)

"Mungkin teman seperti ini. Pelaksanaan supervisi ini di masing-masing itu tidak terpisah ya. Edukasi-edukasi, yang lain, yang lain. Pada umumnya kita lakukan sekaligus. Sejalan semuanya dengan asuhan" (Partisipan 5) 
"Ya. Secara tiba-tiba aja. Terus sekaligus tanpa ada perencanaan" (Partisipan 10)

"Kalau supervisinya tidak terlalu terasa. Maksudnya supervisi yang langsung ke lapangan. Biasanya sih waktu kita lagi operan pagi kan ya disitu diingatkan edukasi ya pasiennya untuk personal hygiene gitu misalnya atau edukasi untuk barangbarang, rapikan kondisi dilingkungan pasien terus edukasi buang urine. Itu diingatkan di operan pagi. Tapi kadang sambil operan berjalan kadang kita sampaikan ibu begini ya, begini, begini tapi tidak ada yang memang benar benar khusus supervisi untuk edukasi itu” (Partisipan 22)

"Biasanya supervisi itu disini dilakukan saat ada penghambat yang harus kita bicarakan bersama" (Partisipan 18)

\section{Tema 3: Kendala yang Dialami dalam Melaksanakan Supervisi}

Partisipan menyampaikan bahwa ada beberapa kendala yang dialami dalam melaksanakan supervisi, yaitu (1) pendokumentasian, (2) tidak memiliki acuan dalam melakukan supervisi, dan (3) belum disediakan waktu khusus untuk supervisi. Berikut pernyataan langsung dari partisipan:

"Pada dasarnya bagus. Tapi, kembali lagi tapi kalau balik kita hubungkan ke konsep, di bilangkan kalau supervisi itu ehmmm. ada kontrak waktu. Kan gitu kan. Ada kontrak materi, dan lain-lainnya. Jadi, disitu masih kelemahan kita dipendokumentasian" (Partisipan 1)

"Kita belum punya tools yang baku yang digunakan. Mau ditindakan manapun kami belum punya itu. Jadi kami menilainya tidak ada standarnya. Jadi seperti itu” (Partisipan 5)

"Kalau kita disini yang rutin kita lakukan itu ya rapat bulanan aja. kalau waktu khusus untuk supervisi itu belum ada" (Partisipan 18)

\section{Tema 4: Harapan Kedepan Terkait Pelaksanaan Supervisi}

Partisipan menyampaikan ada beberapa harapan terkait pelaksanaan supervisi, yakni tersediannya acuan dalam melakukan supervisi, adanya pertemuan rutin, adanya kerjasama dalam tim, pihak yang melakukan supervisi memiliki kompetensi dan pelayanan pasien semakin baik. Berikut pernyataan langsung dari partisipan:

"Harapannya ya ada pertemuan rutin lah untuk membicarakan problem diruangan sehingga dapat memberikan solusi”" (Partisipan 18)

"Harapannya sih kalau memang ada rencana supervisi ya rutin saja dikerjakan ya mau perbulan atau gimana ceritanya. Ya dikerjakan saja toh untuk kebaikan bersama kan supervisinya.." (Partisipan 22)

"Tapi maunya ada kerjasama. Ada kerjasama tim karena nantinya juga kita perlu pendapat mereka, apa atau bagaimana yang perlu dikembangkan. Itu untuk pengembangan diri sendiri" (Partisipan 17) 
"Terus harapannya yang melaksanakannya orang yang benar-benar kompeten tidak dengan 1 hal saja tapi semua bisa dikelola” (Partisipan 18)

"Hmm apalagi ya, pelayanan ke pasien tetap diusahakan tetap lebih baik. Itu sih.." (Partisipan 22)

\section{Tema 5: Manfaat Pelaksanaan Supervisi}

Partisipan menyampaikan manfaat pelaksanaan supervisi untuk perawat, yaitu perawat melakukan tindakan sesuai dengan SPO, perawat dapat berkomunikasi dengan baik, perawat memiliki emosional yang terkontrol, perawat dapat sharing dengan supervisor, perawat dapat semakin memperbaiki diri, saran dari perawat dapat diterima, perawat semakin nyaman dalam bekerja, pemahaman perawat semakin meningkat, dan kepatuhan perawat terhadap pemberian edukasi meningkat. Berikut pernyataan langsung dari partisipan:

"Nanti apa yang dikerjakan itu ya sesuai dengan SPO dan sesuai dengan dokumentasi yang sudah dilakukan. Bahwa apa yang telah dia kerjakan, sama dengan apa yang telah tertulis" (Partisipan 6)

"Ehmm.. kita tetap bisa melakukan sesuatu sesuai dengan SOP" (Partisipan 18)

"Jadi di diskusi itu, mereka selalu menampung aspirasi kita, bagaimana ini, bagaimana itu.. Kita bisa menyampaikan apa yang dirasakan pasien dan apa yang kita rasakan" (Partisipan 17)

"Kalau itu ada dan dilakukan, pasti perawatnya lebih paham, lebih mengerti lah. Karena otomatis kan informasi terbaru kan akan disampaikan. Kalau nanti itu dilakukan misalnya setiap bulan, maka pasti itu akan terarah" (Partisipan 17)

"Jadi kan bisa dikasih tahu kekurangan kita dimana. Terus mereka juga bisa kasih masukan. Jadi pengetahuan kita nambah, mana yang harus diperbaiki gitu” (Partisipan 21)

"Menurut saya perlu sih, karena ya kayak tadi semangatnya lagi turun. Kadang kan kita kalau ada yang supervisi, ada yang mengawasi harusnya kita lebih patuh. Walaupun harusnya jangan karena disupervisi jadinya kita baru patuh. Maunya jangan begitu. Tapi menurutku sih perlu diawasi biar edukasi tetap berjalan dan lama-lama jadi kebiasaan jadi tabiat gitu. Jadi nanti edukasi itu dilakukan sesuai dengan yang seharusnya" (Partisipan 22)

\section{PEMBAHASAN}

Hasil dari penelitian ini menunjukkan gambaran persepsi perawat tentang kegiatan supervisi klinis dalam konteks pelaksanaan edukasi pasien dan keluarga. Tema pertama menunjukkan tujuan dari adanya kegiatan supervisi klinis. Partisipan mengungkapkan bahwa supervisi klinis merupakan suatu hal yang penting untuk dilakukan agar dapat menilai kemampuan perawat dalam menyampaikan informasi kesehatan pada pasien, untuk memantau dokumentasi pemberian edukasi, meningkatkan kepercayaan diri perawat, edukasi yang disampaikan perawat semakin jelas, pelayanan keperawatan lebih bermutu dan efisien, meningkatkan pengetahuan dan pemahaman perawat, pasien lebih mengenal perawat yang merawatnya, mencegah terjadinya miskomunikasi dengan 
keluarga pasien, dan agar perawat bekerja sesuai dengan Standar Prosedur Operasional (SPO).

Supervisi klinis merupakan suatu elemen penting untuk memastikan perawatan pasien yang berkualitas tinggi. Supervisi klinis menyediakan pendekatan reflektif terstruktur pada praktik klinis yang dapat mengarah pada peningkatan layanan dengan mengembangkan pengetahuan profesional dalam praktik, mendukung pengembangan keterampilan klinis perawat, meningkatkan standar kualitas asuhan keperawatan, mendukung dan memberdayakan perawat untuk bekerja secara efektif, dan memfasilitasi proses dukungan bagi perawat dari tekanan emosional (Driscoll et al., 2019; Snowdon et al., 2019; West, 2019).

Penelitian Moghadam et al., (2018) yang dilakukan di Iran menunjukkan bahwa setelah adanya pelaksanaan supervisi klinis maka terjadi peningkatan kualitas dokumentasi pada edukasi pasien dan meningkatkan respon perawat terhadap kebutuhan edukasi pasien, yang pada gilirannya dapat meningkatkan kepuasan pasien.

Tema kedua yang dihasilkan dari penelitian ini, yaitu metode dalam melaksanakan kegiatan supervisi. Partisipan mengungkapkan bahwa kegiatan supervisi klinis dilakukan secara situasional, supervisi dilakukan secara tiba-tiba atau tanpa perencanaan, supervisi dilakukan pada saat operan atau dilakukan jika ada masalah dalam hal pemberian edukasi diruangan. Hal tersebut sejalan dengan Penelitian Anggeria, Maria (2018) yang dilakukan di Rumah Sakit Royal Prima Medan, yang menunjukkan bahwa kepala ruangan melakukan supervisi pada saat operan. Selain itu, penelitian Oktaviani, Rofii (2019) juga menyatakan bahwa kegiatan supervisi di Rumah Sakit Semarang juga masih bersifat insidential sesuai dengan kebutuhan dan belum dilaksanakan secara terstruktur dan terdokumentasi dengan baik. Idealnya, supervisi klinis dilakukan secara teratur dan terjadwal.

Kegiatan supervisi klinis dirumah sakit masih belum dapat dilakukan dengan baik dikarenakan ada beberapa kendala yang dialami. Ada beberapa kendala yang diungkapkan oleh partisipan, yakni belum tersedianya formulir untuk pendokumentasian supervisi, belum adanya acuan atau pedoman dalam melakukan supervisi, dan juga belum tersedianya waktu khusus untuk melaksanakan supervisi. Hal ini sejalan dengan penelitian Oktaviani, Rofii (2019) yang menunjukkan bahwa pelaksanaan supervisi di Rumah Sakit Semarang memiliki kendala dikarenakan belum adanya instrumen penilaian, panduan, dokumentasi hasil supervisi, dan Standar Prosedur Operasional (SPO) supervisi. Sementara itu, penelitian Snowdon et al., (2019) menunjukkan bahwa menemukan atau menyediakan waktu khusus masih menjadi penghalang dalam melakukan supervisi klinis sehingga hal ini menjadi masalah dan berdampak pada perawatan pasien. Oleh karena itu, solusinya mungkin melibatkan pihak menajemen agar dapat memberikan waktu untuk supervisi dan memastikan bahwa supervisor memiliki keterampilan dan akuntabilitas dalam menjalankan peran sebagai seorang supervisor.

Supervisi klinis apabila dilakukan secara efektif pada perawat dapat memberikan manfaat bagi suatu rumah sakit. Penelitian ini menunjukkan ada beberapa manfaat yang didapatkan jika supervisi dilakukan dengan baik, yaitu pemahaman perawat dapat meningkat, perawat akan melakukan tindakan sesuai dengan SPO, sesuai yang didokumentasikan dengan yang dilakukan perawat, komunikasi perawat menjadi baik, emosional perawat terkontrol, perawat dapat sharing dengan supervisor, perawat semakin memperbaiki diri, saran dari perawat dapat diterima, perawat semakin nyaman dalam bekerja, dan kepatuhan perawat terhadap pemberian edukasi meningkat. 
Butterworth, Shaw (2017) menyatakan bahwa kegiatan supervisi klinis memberikan manfaat bagi perawat pelaksana, yakni sebagai media dalam berbagi pengetahuan dan keterampilan dengan rekan-rekan perawat maupun dengan perawat yang lebih berpengalaman. Marwiati, Komsiyah (2017) menambahkan bahwa supervisi klinis dapat meningkatkan kompetensi perawat dalam pemberian asuhan, meningkatkan rasa empati, responsivitas dan tanggung jawab perawat. Supervisi klinis juga dapat memberikan pengetahuan baru, inisiasi langkah baru (inovasi) dan meningkatkan hubungan yang harmonis dalam bekerja serta dapat meningkatkan kompetensi perawat pelaksana. Hall (2018) menambahkan bahwa supervisi klinis dapat menjadi langkah yang benar karena perawat diberikan waktu khusus untuk berdiskusi dan merefleksikan cara yang diberikan oleh supervisor. Perawat yang merasa didukung untuk berefleksi secara mendalam lebih siap untuk memberikan perawatan yang baik yang berpusat pada pasien.

Beberapa literature telah menunjukkan bahwa supervisi klinis merupakan suatu kegiatan yang bermanfaat baik bagi perawat, pasien maupun organisasi. Oleh karena itu, partisipan dalam penelitian ini memiliki harapan agar tersedianya acuan atau pedoman supervisi klinis, adanya pertemuan rutin untuk melakukan supervisi, adanya kerjasama dalam tim, dan pihak ataupun orang yang melakukan supervisi sebaiknya berkompeten. Snowdon et al., (2019) menyatakan bahwa adanya pedoman yang jelas yang menguraikan peran supervisi klinis dapat secara positif mempengaruhi penerimaan dan model praktik supervisi klinis secara langsung. Seorang pelaksana supervisi atau yang disebut dengan supervisor klinis haruslah memiliki keterampilan dan perlengkapan yang diperlukan untuk memfasilitasi kegiatan supervisi yang konstruktif. Oleh karena itu, hal yang terpenting untuk diidentifikasi, yaitu supervisor menghargai proses supervisi dan memberikan waktu untuk melakukan kegiatan supervisi.

\section{SIMPULAN}

Hasil penelitian ini menghasilkan 5 tema mengenai persepsi perawat tentang pelaksanaan supervisi klinis yang dilakukan di Rumah Sakit Universitas Sumatera Utara, yaitu (1) tujuan dilakukannya supervisi terkait pelaksanaan edukasi pasien dan keluarga, (2) metode dalam melaksanakan supervisi, (3) kendala yang dialami dalam melaksanakan supervisi, (4) harapan kedepan terkait pelaksanaan supervisi dan (5) manfaat pelaksanaan supervisi. Persepsi perawat terhadap kegiatan supervsi klinis pelaksanaan edukasi pasien dan keluarga penting dilakukan untuk mendukung praktik keperawatan meskipun dalam pelaksanaannya masih belum dilakukan secara optimal.

\section{SARAN}

Pihak manajemen sebaiknya memiliki komitmen dan peran aktif untuk dapat melaksanakan kegiatan supervisi klinis secara rutin atau berkala dalam upaya memberikan bimbingan dan arahan untuk perawat agar semakin termotivasi dalam melakukan pemberian edukasi pada pasien dan keluarga. Peneliti juga merekomendasikan agar pelaksana supervisi (supervisor) mendapatkan pelatihan ataupun seminar mengenai topik supervisi klinis supaya pengetahuan dan kompetensi supervisor semakin lebih baik sehingga dapat melaksanakan perannya secara efektif. 


\section{DAFTAR PUSTAKA}

Anggeria, E., \& Maria, M. (2018). Hubungan Supervisi dengan Pelaksanaan Asuhan Keperawatan di Ruang Rawat Inap Lantai 10 Rumah Sakit Umum Royal Prima Medan Tahun 2017. Jumantik: Jurnal Ilmiah Penelitian Kesehatan, 3(2), 63-63. https://doi.org/10.3778/j.issn.1002-8331.2010.09.018

Bradley, I. A. (2019). More Nurse Supervisors Wanted. Kai Tiaki Nursing New Zealand, 25(9), 34-35

Butterworth, T., \& Shaw, T. (2017). Playing Our Part the Work of Graduate and Registered Mental Health Nurses an Independent Review by the Foundation of Nursing Studies (pp. 1-25). https://www.fons.org/resources/documents/ReportPlaying-our-Part,-the-work-of-graduate-and-registered-mental-health-nurses.pdf

Cutcliffe, J. R., Sloan, G., \& Bashaw, M. (2018). A Systematic Review of Clinical Supervision Evaluation Studies in Nursing. International Journal of Mental Health Nursing, 27(5), 1344-1363. https://doi.org/10.1111/inm.12443

Desi, H. D., Sumaryani, S., \& Maria, R. E. (2017). Evaluasi Pelaksanaan Supervisi Keperawatan di Rumah Sakit Umum Daerah Panembahan Senopati Bantul. Jurnal Medicoeticolegal dan Manajemen Rumah Sakit 10.18196/jmmr.2016, 6(1), 47-54. https://doi.org/10.18196/jmmr.6126

Driscoll, J., Stacey, G., Harrison-Dening, K., Boyd, C., \& Shaw, T. (2019). Enhancing the Quality of Clinical Supervision in Nursing Practice. Nursing Standard (Royal College of Nursing (Great Britain): 1987), 34(5), 43-50. https://doi.org/10.7748/ns.2019.e11228

Hall, I. (2018). Implementing a Sustainable Clinical Supervision Model for Isles Nurses in Orkney. British Journal of Community Nursing, 23(3), 136-139. https://doi.org/10.12968/bjen.2018.23.3.136

Heshmati, N. F., Rajabpoor, M., Mahmoodi, J., Pouresmail, Z., \& Mikaniki, T. (2016). Comparing the Patient's Satisfaction With Educational Performance of the Physicians and the Nurses. Jundishapur Journal of Chronic Disease Care, 5(1). https://doi.org/10.17795/jjcdc-29190

KARS. (2018). Standar Nasional Akreditasi Rumah Sakit Efektif 1 Januari 2018. Standar Nasional Akreditasi Rumah Sakit

Livne, Y., Peterfreund, I., \& Sheps, J. (2017). Barriers to Patient Education and Their Relationship to Nurses' Perceptions of Patient Education Climate. Clinical Nursing Studies, 5(4), 65. https://doi.org/10.5430/cns.v5n4p65

Marwiati, M., \& Komsiyah, K. (2017). Efektifitas Supervisi Klinis dalam Peningkatan Kompetensi Perawat Pelaksana: Systematic Review. Jurnal Penelitian dan Pengabdian Kepada Masyarakat UNSIQ, 4(3), 213-219. https://doi.org/10.32699/ppkm.v4i3.426

McCarron, R. H., Eade, J., \& Delmage, E. (2018). The Experience of Clinical Supervision for Nurses and Healthcare Assistants in a Secure Adolescent Service: Affecting Service Improvement. Journal of Psychiatric and Mental Health Nursing, 25(3), 145-156. https://doi.org/10.1111/jpm.12447

Moghadam, A. J., Nabavi, F. H., Behboudifar, A., Mazlom, S. R., \& Heydarian, F. (2018). Impact of Group Clinical Supervision on Patient Education Process: A Comprehensive Assessment of Patients, Staff, and Organization Dimensions. Evidence Based Care Journal, 8(1), 17-26. https://doi.org/10.22038/ebcj.2018.30316.1753 
Ning, T. J., \& Costello, J. (2017). Implementing Clinical Nursing Supervision in Singapore Hospitals. 111-114. https://doi.org/10.5176/2315-4330_wnc17.76

Nuritasari, R. T., Rofiqi, E., Fibriola, T. N., \& Ardiansyah, R. T. (2020). The Effect of Clinical Supervision on Nurse Performance. Jurnal Ners, 14(3), 161. https://doi.org/10.20473/jn.v14i3.16956

Oktaviani, M. H., \& Rofii, M. (2019). Gambaran Pelaksanaan Supervisi Kepala Ruang terhadap Perawat Pelaksana dalam Keselamatan Pasien. Jurnal Kepemimpinan dan Manajemen Keperawatan, 2(1), 23. https://doi.org/10.32584/jkmk.v2i1.165

Schaffarczyk, K. (2018). Clinical Supervision in a Large Teaching Hospital: The Dawn of a New Era. https://www.acn.edu.au/nurseclick/clinical-supervision-in-a-largeteaching-hospital-the-dawn-of-a-new-era\#comments

Snowdon, D. A., Sargent, M., Williams, C. M., Maloney, S., Caspers, K., \& Taylor, N. F. (2019). Effective Clinical Supervision of Allied Health Professionals: A Mixed Methods Study. BMC Health Services Research, 20(1). https://doi.org/10.1186/s12913-019-4873-8

West, W. M. (2019). Guidance Document on Peer Group Clinical Supervision Health Service Executive. https://healthservice.hse.ie/about-us/onmsd/onmsd/nursingmidwifery-planning-development/guidance-document-on-peer-group-clinicalsupervision-nmpdu-hse-west-mid-west-2019.pdf

Yuswanto, T. J. A., Ernawati, N., \& Rajiani, I. (2018). The Effectiveness of Clinical Supervision Model Based on Proctor Theory and Interpersonal Relationship Cycle (Pir-c) Toward Nurses' Performance in Improving the Quality of Nursing Care Documentation. Indian Journal of Public Health Research and Development, 9(10), 561-566. https://doi.org/10.5958/0976-5506.2018.01405.5 